EESTI NSV TEADUSTE AKADEEMIA TOIMETISED, XVIII KÖIDE

KEEMIA * GEOLOOGIA, 1969, Nr. 4

ИЗВЕСТИЯ АКАДЕМИИ НАУК ЭСТОНСКОИ ССР. ТОМ ХVII

ХИМИЯ * ГЕОЛОГИя. 1969, 스 4

Ю. ЛИЛЛЕ, Л. БИТТЕР, Х. КУНДЕЛЬ, А. МУРД, У. ПЕИНАР

\title{
О ВЫДЕЛЕНИИ АЛКИЛРЕЗОРЦИНОВ ИЗ СЛАНЦЕВЫХ ВОДОРАСТВОРИМЫХ ФЕНОЛОВ
}

Синтез 5-замещенных алкилрезорцинов ссстоит из 4-5 стадий $\left[{ }^{1,2}\right]$ и поэтому общий выход продукта составляет не более $10-15 \%$. Сланцевые двухатомные фенолы являются в основном 5-замещенными алкилрезорцинами $\left[{ }^{3,4}\right]$. Например, во второй фракции водорастворимых фенолов, кипящих в пределах $275-310^{\circ} \mathrm{C}$, содержится до 50\% 5-метил- и 5-этилрезорцина. Поэтому разработка препаративных методов выделения индивидуальных алкилрезорцинов из этих фенолов имеет определенное значение.

Для выделения 5-метил- и 2,5-диметилрезорцина из сланцевых водорастворимых фенолов применяется селективная кристаллизация $\left[{ }^{5,6}\right]$. Авторы данного сообщения использовали для выделения алкилрезорцинов метод ректифнкации. До сих пор этим методсм не удалось выделить из водорастворимых фенолов в достаточно чистом виде тлавного индивидуального соединения -5 -метилрезорцина $\left[{ }^{7,8}\right]$, по всей вероятности, из-за нерегулярностей в системе жидкость-пар.

Для улучшения условий ректификации было проведено разделение фенолов в виде термкчески устойчивых и легко гидролизуемых триметилсилиловых эфиров.

Триметилсилилирование фракции водорастворимых фенолов гексаметилдисилазаном проходило гладко. Из 250,0 г исходных фенолов было получено 483,5 г эфиров ( $94,6 \%$ от теоретического). Выход фракции триметилсилиловых эфиров при ректификации составил $94 \%$ от загрузки (рис. 1). Данные газохроматографического анализа показали, что глав-

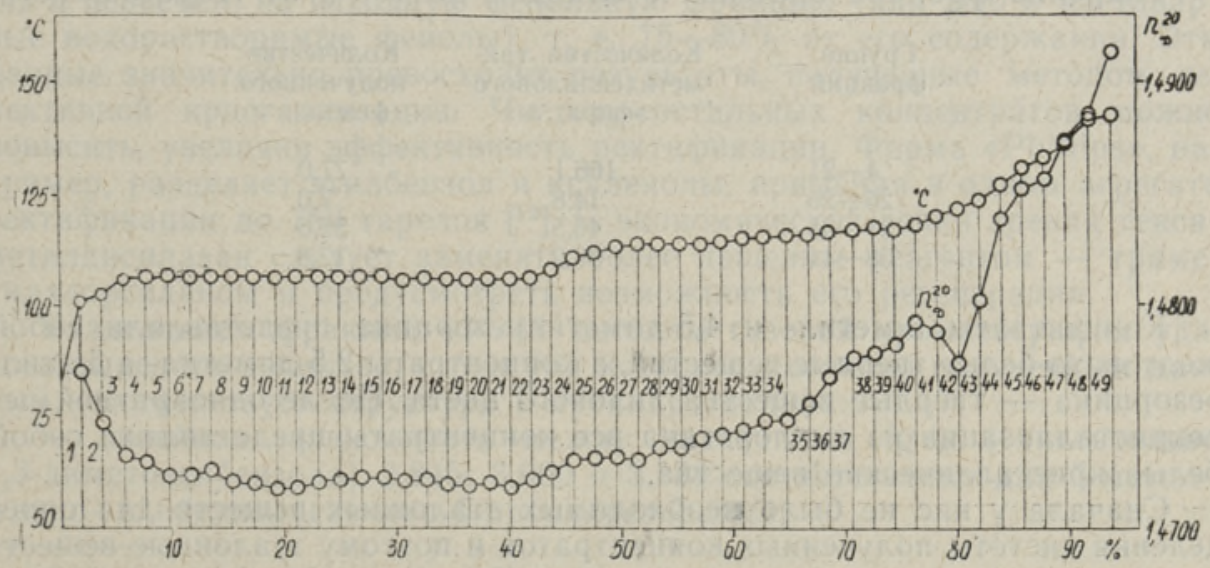

Рис. 1. Результаты ректификации триметилсилиловых эфиров фенолов. 
Результаты газохроматографического анализа фракции триметилсилиловых эфиров фенолов

\begin{tabular}{|c|c|c|c|c|c|c|}
\hline \multirow{2}{*}{$\begin{array}{l}\text { Номер } \\
\text { фракции }\end{array}$} & \multicolumn{6}{|c|}{ Сосгав фракции, \% } \\
\hline & $\begin{array}{l}\text { 5-Мети.]- } \\
\text { резорцин }\end{array}$ & 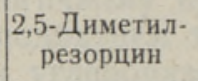 & $\begin{array}{c}\text { 5-Этил- } \\
\text { резорцин }\end{array}$ & $\begin{array}{c}\text { 4,5-Диметил- } \\
\text { резорцин }\end{array}$ & $\begin{array}{l}\text { 5-Пропил- } \\
\text { резорцнн }\end{array}$ & $\begin{array}{l}\text { Осталь- } \\
\text { ные }\end{array}$ \\
\hline 4 & 98,0 & - & - & - & - & 2,0 \\
\hline 13 & 97,3 & 2,2 & 0,5 & - & - & - \\
\hline 22 & 95,2 & 3,9 & 0,4 & - & - & 0,5 \\
\hline 23 & 83,5 & 13,7 & 2,3 & - & - & 0,5 \\
\hline 24 & 51,5 & 37,9 & 8,8 & 1,1 & - & 0,7 \\
\hline 25 & 18,4 & 61,7 & 17,8 & 1,7 & - & 0,4 \\
\hline 26 & 8,3 & 65,4 & 24,0 & 2,3 & - & - \\
\hline 27 & 2,8 & 63,8 & 30,6 & 2,8 & - & - \\
\hline 28 & 1,6 & 63,2 & 32,0 & 3,2 & - & - \\
\hline 29 & 0,5 & 56,2 & 38,8 & 4,5 & - & - \\
\hline 30 & 0,4 & 51,5 & 42,3 & 5,8 & - & - \\
\hline 31 & 0,2 & 40,1 & 51,5 & 8,2 & - & - \\
\hline 32 & - & 30,4 & 58,4 & 11,2 & - & - \\
\hline 33 & - & 30,5 & 54,3 & 15,2 & - & - \\
\hline 34 & - & 18,1 & 59,2 & 22,0 & 0,7 & - \\
\hline 35 & - & 14,6 & 54,6 & 29,9 & 0,9 & - \\
\hline 36 & - & 10,5 & 45,5 & 42,0 & 2,0 & - \\
\hline 37 & - & 7,5 & 34,0 & 54,5 & 4,0 & - \\
\hline 38 & - & 4,2 & 14,8 & 75,8 & 5,2 & - \\
\hline 39 & - & 1,8 & 7,2 & 84,9 & $6, \mathrm{I}$ & - \\
\hline 40 & - & - & 3,5 & 86,4 & 5,1 & 5,0 \\
\hline 41 & - & - & 0,2 & 81,4 & 6,2 & 12,2 \\
\hline 42 & - & - & - & 47,7 & 10,8 & 41,5 \\
\hline 44 & - & - & - & 8,8 & 22,7 & 68,5 \\
\hline 45 & - & - & - & 1,3 & 5,2 & $93,5$. \\
\hline 47 & - & - & - & - & - & 100 \\
\hline
\end{tabular}

ные индивидуальные соединения водорастворимых фенолов - 5-метил-, 2,5-диметил-, 5-этил- и 4,5-диметилрезорцин - концентрировались соответственно во фракциях $5-21,25-28,31-35$ и $38-41$ (табл. 1). Oтметим, что в примененных нами условиях анализа разделяются не все изомеры фенолов, однако в данном случае это не имело существенного значения, поскольку анализы использовались лишь для группировки фракций с целью их последующего совместного гидролиза.

Гидролиз фракций протекал с выходом до 100\% от теоретического:

$\begin{array}{ccc}\text { Группа } & \begin{array}{l}\text { Количество три- } \\ \text { фракций } \\ \text { метилсилилового }\end{array} & \text { Количество } \\ \text { полученного } \\ \text { фенола, 2 }\end{array}$

$\begin{array}{rrr}4-21 & 166,1 & 77,0 \\ 25-26 & 14,8 & 7,0 \\ 31-35 & 46,5 & 22,6 \\ 38-41 & 36,2 & 17,8\end{array}$

Концентраты 5-метил- и 4,5-диметилрезорцина представляли собой желтовато-белые твердые вещества, а концентраты 2,5-диметил- и 5-этилрезорцина - твердые вещества лилового цвета. После однократной перекристаллизации из дихлорэтана все концентраты представляли собой белые кристаллические вещества.

Сначала у нас не было необходимых эталонных веществ для определения чистоты полученных концентратов и поэтому эталонные вещества выделяли из самих водорастворимых фенолов по схеме: разделение О-метилированной фракции фенолов методом газовой хроматографии - 
расщепление диметиловых эфиров алкилрезорцинов-очистка алкилрезорцинов на тонком слое силикагеля. В применяемых условиях газохроматографического анализа были разделены все четыре изомерных диметилрезорцина.

ИК-спектры полученных таким путем алкилрезорцинов изображены на рис. 2 и 3. Спектр 5-метилрезорцина соответствует спектру этого вещества в каталоге [9]. Спектров остальных алкилрезорцинов в этом и других доступных нам каталогах $\left[{ }^{10,11}\right]$ не имеется.*

ИК-спектры концентратов, выделенных ректификацией (табл. 2), в основном совпадают со спектрами эталонов. Методом газовой хроматографии определено следующее содержание (в процентах) основного вещества в концентратах:

5-мегилрезорцин 2,5-диметилрезорцин 5-этилрезорцин 4,5-диметилрезорцин
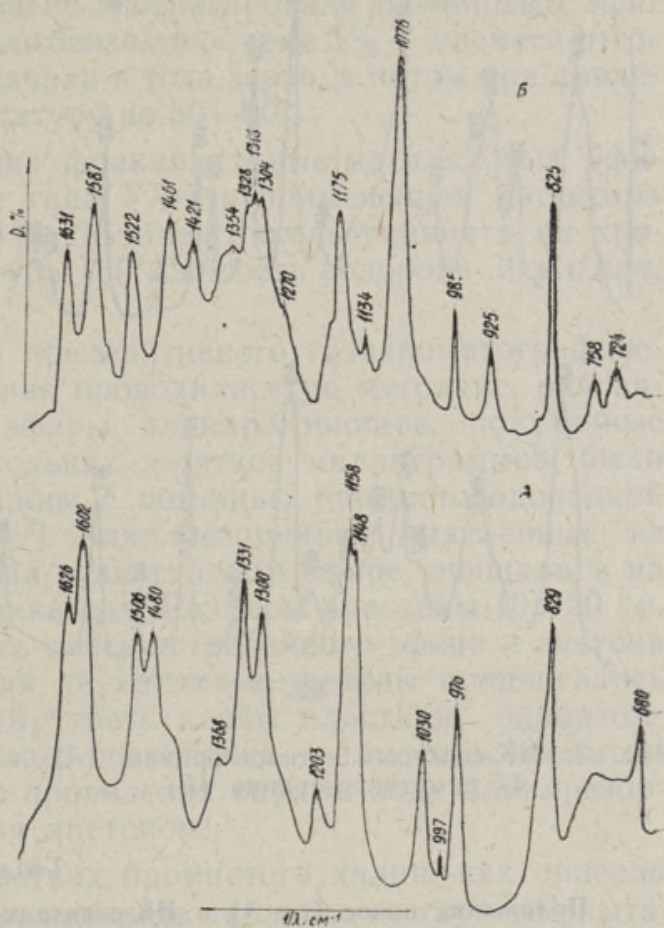

Рис. 2. ИК-спектры 5-метилрезорцина (A) и. 2,5-диметилрезорцина $(\bar{D})$.

Способ анализа

$\begin{array}{rcrc}1 & 2 & 3 & 4 \\ 100 & 100 & 100 & 99 \\ 88 & \text { He onр. } & 76 & 80 \\ 72 & " \quad, & 78 & 58 \\ 100 & , \quad, \quad & 94 & 96\end{array}$

Результаты анализов 5-метилрезорцина до и после перекристаллизации из дихлорэтана практически не отличались.

Таким образсм, удалось выделить 30,8\% 5-метилрезорцина марки «ч» в пересчете на исходную фенольную фракцию (или 20,0\% на товарнье водорастворимые фенолы), т. е. $75-80 \%$ от его содержания. Эти данные значительно превосходят результаты, полученные методом селективной кристаллизации. Чистоту остальных концентратов можно повысить, увеличив эффективность ректификации. Фирма «Phillips», например, разделяет этилбензол и ксиленолы, применяя в одном агрегате ректификации до 750 тарелок $\left[{ }^{12}\right]$. С экономической точки зрения гексаметилдисилазан следует заменить более дешевым реагентом - триметилхлорсиланом и предусмотреть возможность его регенерации.

Разделением фракций 43--44 методом газовой хроматографии удалось выделить вещество, структура которого, согласно полученным данным, соответствует структуре 5-пропилрезорцина:

- линейная зависимость между значениями $\lg t_{R}$ (относительно 1,3-диметоксибензола) 2,845; 3,000 и 3,158 соответственно для 5-метил-, 5-этил- и предполагаемого 5-пропилрезорцина;

* Спектры 2,5-, 4,5-диметил- и 5-этилрезорцина совпадают со спектрами синтезирсванных позже эталснных веществ. 


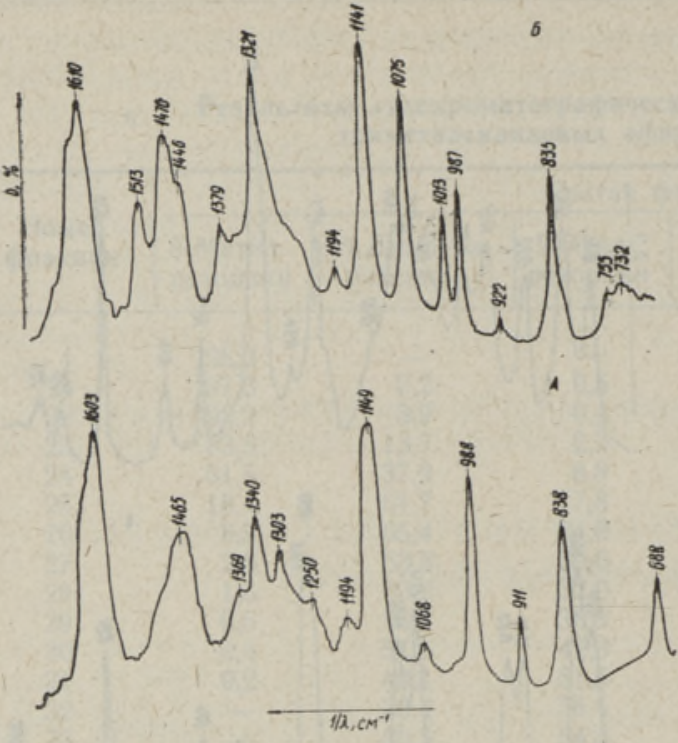

- максимумы в УФ-спектре при 273 и 279 нм (как и для метиловых эфиров 5-метил- и 5-этилрезорцина);

- полосы в ИК-спектре при 696 и $830 \mathrm{~cm}^{-2}$ (1,3,5-замещение в ядре);

- при каталитическом деметоксилировании концентрата образовался преимущественно пропилбензол.

Выделение ' алкилрезорцинов с помощью препаративной газовой хроматографии весьма заманчиво, однако, как показывают результаты нашего опыта, стабильность имеющихся в настоящее время разделяющих фаз для этой цели еще недостаточна.

Рис. 3. ИК-спектры 5-этилрезорцина $(A)$ и 4,5-диметилрезсрцина (Б).

Таблица 2

Положение полос $\left(c_{M-1}\right)$ в ИК-спектрах концентратов индивидуальных соединений, выделенных ректификацией в виде триметилсилиловых эфиров

\begin{tabular}{|c|c|c|c|}
\hline $\begin{array}{l}\text { 5-Метил- } \\
\text { резорцин }\end{array}$ & $\begin{array}{c}\text { 2,5-Диметил- } \\
\text { резорцин }\end{array}$ & $\begin{array}{l}\text { 5-Этнл- } \\
\text { резорцин }\end{array}$ & $\begin{array}{c}\text { 4,5-Диметил- } \\
\text { резорцин }\end{array}$ \\
\hline 678 (ср) & 684 (сл) & 688 (cp) & 729 (сл) \\
\hline 825 (сp) & 719 (сл) & 838 (c) & 832 (cp) \\
\hline 842 ( $\left.\mathrm{C}_{\text {iI }}\right)$ & 754 (сл) & 906 (сл) & 919 (сл) \\
\hline 971 (cp) & 822 (сp) & 988 (c) & 984 (cp) \\
\hline 996 (сл) & & & \\
\hline $1030(\mathrm{cp})$ & 920 (сл) & $1076(\mathrm{cp})$ & $1012(\mathrm{cp})$ \\
\hline 1149 (c) & 980 (сp) & 1150 (c) & 1079 (c) \\
\hline 1207 (сл) & 1076 (c) & 1251 (cp) & 1143 (c) \\
\hline $1306(\mathrm{cp})$ & 1146 (cp) & 1308 (c) & 1191 (сл) \\
\hline $1315(\mathrm{cp})$ & 1176 (сp) & 1333 (c) & 1320 (c) \\
\hline 1330 (c) & $1316(c)$ & $\begin{array}{l}1468 \text { (с) } \\
1363 \text { (сл) }\end{array}$ & $1380(\mathrm{cp})$ \\
\hline $1374(\mathrm{cp})$ & $1359(\mathrm{cp})$ & 1499 (ср) & 1440 (ср) \\
\hline 1478 (c) & $1420(\mathrm{cp})$ & 1599 (c) & 1468 (c) \\
\hline $1512(\mathrm{cp})$ & 1456 (ср) & 1618 (cp) & $1517(\mathrm{cp})$ \\
\hline 1602 (c) & 1520 (ср) & & 1609 (c) \\
\hline $1627(\mathrm{c})$ & 1581 (ср) & & $1628(\mathrm{cp})$ \\
\hline & $\begin{array}{l}1626(\mathrm{cp}) \\
1670(\mathrm{cл})\end{array}$ & & \\
\hline & 1702 (сл) & & \\
\hline
\end{tabular}

При меч ани е. с - сильная, ср - средняя, сл - слабая. числе $40: 1$. Для гидролиза на 1 г фракции эфиров добавляли 3,5 мл $10 \%$-ной соляной кислоты и смесь перемешивали при температуре $20-25^{a}$ 
в течение 2 ч. Затем смесь пятикратно экстрагировали диэтиловым эфиром, к эфирной вытяжке прибавляли бензол в объеме $5 \%$ и из смеси отгоняли растворители и силоксаны сначала в токе азота, а потом при давлении 10 мм рт. ст., поднимая температуру до $50-60^{\circ}$.

Газохроматографический анализ фракции триметилсилиловых эфиров проводился на хроматографе типа УХ-2 с применением детектора теплопроводности и колонки с $15 \%$ диэтиленгликольсукцината на хромосорбе $W, 0,35 \times 300 \mathrm{~cm}$. Температура $160^{\circ}$, скорость водорода $30 \mathrm{M} / \mathrm{Muн}$, величина пробы 2 мг.

О-метилирование фенолов для препаративного газохроматографического разделения и само разделение проводились по методике, описанной нами ранее [ $\left.{ }^{4}\right]$. Метиловые эфиры алкилрезорцинов, полученныс этим способом в количестве нескольких десятков миллиграммов, были снова превращены в алкилрезорцины с помощью бромистоводородной кислоты по известной методике [13]. Алкилрезорцины, выделенные из реакционной смеси в виде раствора в диэтиловом эфире, очищались на незакрепленном слое $(0,5$ мм) силикагеля. Размеры пластины $10 \times 20 \mathrm{~cm}$. В качестве элюента использовалась смесь петролейного эфира и ацетона 3:1. В данной системе разделения двухатомные фенолы продвигались от линии старта примерно на одну треть длины пластины, одноатомные - на две трети, а нейтральные соединения - вместе с фронтом элюента. После кратковременного проявления парами йода алкилрезорцин экстрагировали от силикагеля ацетоном.

ИК-спектры снимались в таблетках бромистого калия, как описано в работе [4]. В качестве эталона применялась таблетка из глухого опыта. Методика проверялась получением из 1,3-диметоксибензола резорцина и снятием его ИК-спектра.

Газохроматографический анализ концентратов алкилрезорцинов проводился на хроматографе GC-1C фирмы «Шимадзу» с применением пламенно-ионизационного детектора и колонки с $2 \%$ апьезона на шималите $F, 0,3 \times 261,5$ см в следующих условиях:

1. В виде фенолов. Температура колонки, испарителя и детектора соответственно 180,250 и $250^{\circ}$, скорость азота $30 \mathrm{M} /$ мuн, величина пробы 0.5 мг.

2. В виде метиловых эфиров. Для метилирования 1 г фенола растворяли в 50 мл воды и, используя рН-метр ЛПУ-01, прибавляли 8 н. щелочь до $\mathrm{pH} 9,0-9,2$ при температуре $48-50^{\circ}$. При перемешивании добавляли из бюретки в течение $10-15$ мин 3 мл диметилсульфата, сохраняя значение $\mathrm{pH}$ в указанных пределах прибавлением раствора щелочи. После этого перемешивали раствор при той же температуре и $\mathrm{pH}$ еще 30 мин, затем подщелачивали и трижды экстрагировали диэтиловым эфиром, эфирную вытяжку сушили на сернокислом натрии и эфир отгоняли. Эфиры фенолов анализировали при температуре колонки, испарителя и детектора соответственно 150,250 и $250^{\circ}$. Скорость азота $30 \mathrm{мл/мин,} \mathrm{величина} \mathrm{пробы} 1$ мг. Содержание основного вещества (в процентах), найденное, как обычно, методом внутренней нормализации, разделяют на поправочный коэффициент 0,94 .

3. В виде метиловых эфиров. Метилирование проводилось в испарителе хроматографа. 5 мг фенола растворяли в 90 мкл 2 н. спиртового раствора гидроксида тетраметиламмония, хорошо перемешивали и немедленно подавали $1-2$ мкл раствора в хроматограф. Температура испарителя $300^{\circ}$. Расчет проводился, как указано выше, с применением поправочного коэффициента 0,96 . 
4. В виде триметилсилиловых эфиров. 50 мг фенола растворяли в 0,2 мл гексаметилдисилазана и смесь нагревали с обратным холодильником в течение 2,5 часа при $130^{\circ}$. Условия анализа приведены выне.

Каталитическое деметоксилирование проведено по [ $\left.{ }^{4}\right]$.

\section{Выводы}

Показано, что путем ректификации сланцевых водорастворимых фенолов в виде триметилсилиловых эфиров можно выделить концентраты 5-метил-, 2,5-диметнл-, 5-этил- и 4,5-диметилрезорцинов. 5-метилрезорцин получен с чистотой $99 \%$ в количестве $75-80 \%$ от его потенциального содержания.

\section{ЛИТЕРАТУ РА}

1. Кистенев а М. С., Р о ждественский М. С., Ж. прикл. хим., 22, 1108 (1949).

2. A s a h in a Y., I h a r a S., J. Pharm. Soc. Japan, 48, 12 (1928).

3. Лилле Ю., Кундель Х., Биттер Л., Пейнар У., Бюлл. НТИ, Сланц. н хим. пром. Таллин, № 6, 22 (1966).

4. Лилле Ю. Э., Кундель Х. А., Тр. Ин-та сланцев, вып. 16, 180 (1967).

5. Ря тсеп А. Я., Бухтеев а А. К., Тр. Ин-та сланцев, вып. 16, 186 (1967).

6. А арн а А. Я., Р я тсеп А. Я., Тр. Таллинск. политехн. ин-та, вып. 11 (А 215), $183(1964)$.

7. Лилле Ю., К ундель Х., Бюлл. НТИ, Сланщ. и хим. пром-сть, Таллин, № 6 , 17 (1965).

8. Иванов Б. И., Шаронова Н. Б., Шаманова В. В., Тр. ВНИИТ, вып. 9, $190(1960)$.

9. Beckering W., Fowkes W. W., Infrared Spectra of Hydroxyaromatic Organic Compounds, Washington, 1959.

10. Documentation of Molecular Spectra (DMS), London, Butterworth Publ. [б. г.].

11. Molecular Formula List of Compounds, Names and References to Published Infrared Spectra, ASTM, Special Technical Publication, No. 331, 1963.

12. W i n n F. W., Petroleum Refiner, 39, 109 (1960).

13. Андр н а н в К., Ж. общ. химии, 34,914 (1964).

Институт сланцев (а. Кохтла-Ярве)

Поступнла в редакцию 6/III 1968

\section{O. LILLE, L. BITTER, H. KUNDEL, A. MURD, U. PEINAR}

\section{ALKOULRESORTSIINIDE ERALDAMINE POLLEVKIVIOLLI VEESLAHUSTUVAIST FENOOLIDEST}

Põlevkiviōli veeslahustuvate fenoolide fraktsioon keemispiiridega $154-193^{\circ} \mathrm{C}$ (rōhu! $20 \mathrm{~mm} \mathrm{Hg}$ ) muundati heksametüülsilazaani toimel trimetüülsilüüleetreiks. Eetrid destilleeriti 40:1 tagasijooksu juures. Fraktsioonid analüüsiti gaasikromatograafilisel meetodil ja pärast nende happelist hüdrolüüsi saadi 5-metüül-, 2,5-dimetüül-, 5-etüül- ja 4,5-dimetüülresortsiini kontsentraadid. Saadud 5-metüülresortsiini puhtus on $99 \%$ ja saagis $75-80 \%$ teoreetilisest võimalikust.

\section{O. LILLE, L. BITTER, H. KUNDEL, A. MURD, U. PEINAR}

\section{DIE GEWINNUNG VON ALKYLRESORZINEN AUS WASSERLÖSLICHEN PHENOLEN DES BRENNSCHIEFEROLS}

Eine Fraktion von Phenolen (Siedebereich 154 bis $193^{\circ} \mathrm{C}, 20$ Torr) aus Brennschieferindustrieabwässern wird durch die Einwirkung von Hexamethyldisilazan in Trimethylsilyläther übergeführt und mit dem Rücklaufverhältnis 40:1 destilliert. Die Fraktionen werden mittels der Gaschromatographie analysiert und nach saurer Hydrolyse die Konzentrate von 5-Methyl-, 2,5-Dimethyl-, 5-Äthyl- und 4,5-Dimethylresorzin gewonnen.

Die Ausbeute an 5-Methylresorzin (99\%tiges) beträgt $75-80 \%$. 